\title{
Diskriminierung
}

\section{Keine Angst vor HIV-Patienten!}

\author{
Die Diskriminierung von HIV-Infizierten ist leider auch \\ im Gesundheitswesen immer noch ein Thema. Dabei \\ sind nicht einmal besondere Schutzmaßnahmen nötig.
}

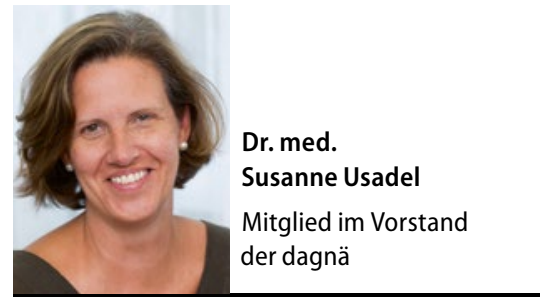

Diese Sorgen und Befürchtungen sind unbegründet. Vielmehr gilt: Für die Behandlung von HIV-Patienten müssen - unabhängig von der Viruslast - in der (Zahnarzt-)Praxis keine zusätzlichen Maßnahmen zur Hygiene und zum Arbeitsschutz getroffen werden. Es genügen die Standardmaßnahmen der $\mathrm{Pa}$ tientenbehandlung und Praxisorganisation. Besondere Kennzeichnungen der Patientenakten wie auch besondere Sprechstunden oder Hygienemaßnahmen sind nicht notwendig. Die „normale“ Reinigung und Desinfektion von

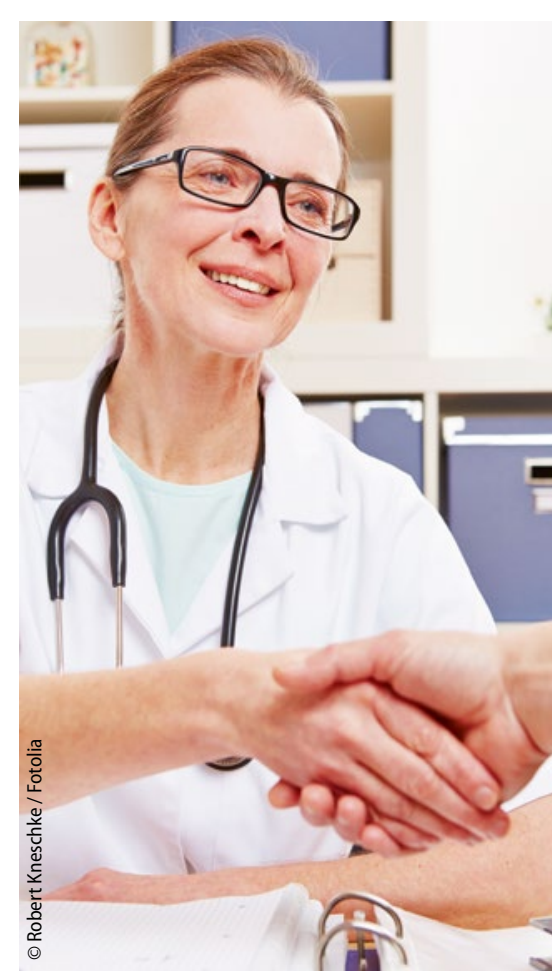

Mit HIV-Positiven können Sie genau so umgehen wie mit den anderen Patienten.
Medizinprodukten und patientennahen Flächen ist ausreichend - genau wie das Tragen üblicher persönlicher Schutzkleidung, etwa wenn die Gefahr des Verspritzens von Flüssigkeiten besteht. Das Ansteckungsrisiko für den Arzt oder die Medizinischen Fachangestellten ist extrem gering. Es gibt nur sehr wenige Fälle von HIV-Erkrankungen nach beruflicher Exposition gegenüber HI-Viren.

\section{Diagnose behutsam vermitteln}

Ansonsten gibt es einige Punkte, in denen die Betreuung von HIV-Patienten ein gewisses Fingerspitzengefühl verlangt. Die Erstdiagnose etwa sollte den Betroffenen stets im persönlichen $\mathrm{Ge}$ spräch mitgeteilt werden. Suizidgedanken sind leider nicht selten. Laut $\$ 7$ Abs. 3 Infektionsschutzgesetz muss die HIVInfektion auch anonymisiert an das Robert-Koch-Institut (RKI) gemeldet werden. Dies macht das diagnostizierende Labor; der einsendende Arzt wird informiert und ergänzt die Angaben zu Epidemiologie und Immunstatus.

Sehr wichtig ist, dass der Patient sich im nächsten Schritt in einer HIVSchwerpunktpraxis vorstellt. Denn die Infektion ist nach wie vor eine komplexe Erkrankung. Die primärärztliche Versorgung kann dann anschließend in enger Abstimmung mit dem HIV-Spezialisten weiterhin beim Hausarzt liegen - nicht zuletzt, um Wechselwirkungen mit den sonstigen Arzneiverordnungen immer im Blick zu haben.

- Die Autorin ist Fachärztin für Allgemeinmedizin/Infektiologie (DGI) und Mitglied im Vorstand der Deutschen Arbeitsgemeinschaft niedergelassener Ärzte in der Versorgung HIV-Infizierter (dagnä, www.dagnae.de) 